\title{
Heat Transfer and Friction Studies in a Tilted and Rib-Roughened Trailing-Edge Cooling Cavity with and without the Trailing-Edge Cooling Holes
}

\author{
M. E. Taslim and J. S. Halabi \\ Mechanical and Industrial Engineering Department, Northeastern University, Boston, MA 02115, USA \\ Correspondence should be addressed to M. E. Taslim; m.taslim@neu.edu
}

Received 5 August 2014; Revised 14 November 2014; Accepted 20 November 2014; Published 14 December 2014

Academic Editor: J-C. Han

Copyright (C) 2014 M. E. Taslim and J. S. Halabi. This is an open access article distributed under the Creative Commons Attribution License, which permits unrestricted use, distribution, and reproduction in any medium, provided the original work is properly cited.

\begin{abstract}
Local and average heat transfer coefficients and friction factors were measured in a test section simulating the trailing-edge cooling cavity of a turbine airfoil. The test rig with a trapezoidal cross-sectional area was rib-roughened on two opposite sides of the trapezoid (airfoil pressure and suction sides) with tapered ribs to conform to the cooling cavity shape and had a 22-degree tilt in the flow direction upstream of the ribs that affected the heat transfer coefficients on the two rib-roughened surfaces. The radial cooling flow traveled from the airfoil root to the tip while exiting through 22 cooling holes along the airfoil trailing-edge. Two rib geometries, with and without the presence of the trailing-edge cooling holes, were examined. The numerical model contained the entire trailing-edge channel, ribs, and trailing-edge cooling holes to simulate exactly the tested geometry. A pressure-correction based, multiblock, multigrid, unstructured/adaptive commercial software was used in this investigation. Realizable $k$ - $\varepsilon$ turbulence model in conjunction with enhanced wall treatment approach for the near wall regions was used for turbulence closure. The applied thermal boundary conditions to the CFD models matched the test boundary conditions. Comparisons are made between the experimental and numerical results.
\end{abstract}

\section{Introduction}

Several cooling features, singly or in combination, have been developed over the years to keep turbine airfoil temperatures below critical levels. The main objective in turbine airfoil internal cooling is usually to achieve maximum heat transfer coefficients while minimizing the coolant flow rate. One such method is to route coolant air through smooth or rib-roughened serpentine passages within the airfoil and convectively remove heat from the airfoil. The coolant is then ejected either at the tip of the airfoil, or through the cooling slots along the trailing edge, or through the film holes on the airfoil surface. Impingement cooling is another effective method of airfoil cooling. In this method, the coolant enters the leading- or trailing-edge cooling cavities in form of jets from the adjacent cavity through a series of crossover holes on the partition wall between the two cavities. The crossover jets impinge on the cavity walls (smooth or rib-roughened) and exit through the film holes on the pressure and suction sides, through the exit holes along the trailing-edge, or form a cross flow in the cavity and move toward the airfoil tip. The reported studies include the work of Chupp et al. [1], Bunker and Metzger [2,3], Chang et al. [4], Akella and Han [5], and Taslim et al. [6-11].

As dictated by the external shape of an airfoil trailingedge, trailing-edge cooling cavities often have very narrow trapezoidal shapes with characteristically small passage aspect ratios. The narrow trapezoidal shape of the trailingedge cooling cavities puts restrictions on the use of ribs. Most of the reported work on the trailing-edge cooling cavities deals with the cooling flow across a pin bank and the ejection of cooling flow through the trailing-edge holes. Metzger et al. [12] reported on heat transfer and flow friction characteristics of very rough transverse ribbed surfaces with and without pin fins. Abuaf et al. [13] reported the results of an experimental investigation of the pressure drop and heat transfer coefficient distributions in serpentine passages with 
and without turbulence promoters. They investigated a threelegged passage with slanted bleed holes along the third leg. Air entered the test section at three inlet ports along the first leg and liquid crystals along with thin foil heaters were used to measure the heat transfer coefficient. Tests were run with and without wooden ribs mounted on the liquid crystals at an angle $90^{\circ}$ with the flow direction. Lau et al. $[14,15]$ reported on turbulent heat transfer and friction in pin fin channels with lateral flow ejection. Kumaran et al. [16] reported on augmented heat transfer in a pin fin channel with short or long ejection holes. Taslim et al. [17] studied the effects of bleed holes on the heat transfer coefficient and friction factor in a rib-roughened trapezoidal passage simulating the trailing-edge cooling cavity of a turbine blade. The ribs were tapered and the cooling flow in the channel was radial. They concluded that there existed a large spanwise variation in heat transfer coefficient in the trailing-edge cavity without the bleed holes. A more uniform distribution of the spanwise heat transfer coefficient was observed in test sections with the bleed holes. Another major conclusion was that the Nusselt number along the channel with bleed holes correlated well with the local Reynolds number.

Impingement on the trailing-edge walls with crossover jets has also been studied by these and other investigators. Taslim and Nicolas [18] reported on an experimental and numerical investigation of jet impingement on ribs in an airfoil trailing-edge cooling channel. In this arrangement, the cooling air enters the trailing-edge cooling cavity from the adjacent cavity through a set of crossover holes and is then ejected through a series of holes along the airfoil trailing-edge and/or a few holes at the airfoil tip. This complex geometry creates a complex flow field. Both longitudinal and spanwise variations in air velocity and heat transfer coefficient are expected. Taslim and coworkers $[19,20]$ reported on a combined experimental and numerical study on crossover jet impingement heat transfer in a narrow trapezoidal channel simulating a typical trailing-edge cooling cavity with smooth and rib-roughened walls. Zero- and five-degree jet angles were tested. Major conclusions in that study were that jets tilted at an angle of 5 degrees produced higher heat transfer coefficients on the target surface. The tilted jets also produced the same level of heat transfer coefficients on the wall opposite the target wall and reasonable agreement was observed between the numerical and experimental results.

All reported studies on heat transfer coefficients pertaining to the trailing-edge cooling cavities deal with straight radial cooling passages. In some airfoil geometries, however, there are cases in which there may be a tilt in the flow passage close to the airfoil tip (in smaller engines), around the dovetail, or in the root area (see Figure 1, top left corner). These step-ups or step-downs can alter the flow structure and, consequently, heat transfer rates on the surfaces immediately downstream the passage tilt. In a smooth channel, the change of flow structure around the channel tilt will alter the heat transfer behavior on the convex and concave walls. In a ribroughened passage, the presence of ribs in the tilted region could alleviate or exasperate the changes in heat transfer coefficients on the two opposite surfaces depending on the rib location in the tilted region. A survey of several existing airfoils revealed that the tilt angle is limited to a range of 15 to 25 degrees. In this investigation, we have concentrated on a 22-degree tilt in an existing trailing-edge cooling cavity and studied the variation of heat transfer coefficients in the cavity around the tilt region for two rib geometries.

\section{Test Section}

Details of the test rig, trailing-edge holes, and ribs are shown in Figures 1 and 2. The steady-state liquid crystal technique was used to measure the heat transfer coefficient on Areas 1 through 5. Before testing, the liquid crystal sheet was calibrated as follows. A water bath was used to attain uniform isochromes on a small sample piece of the liquid crystal sheet used throughout this investigation. The temperature corresponding to each color was measured using a precision thermocouple and photographs were taken at laboratory conditions simultaneously so as to simulate closely the actual testing environment. A reference color along with its measured temperature of $33.78^{\circ} \mathrm{C}$ was then chosen to be used throughout the experiments. It should be noted that all possible shades of the selected reference color showed a temperature difference of no more than $0.3^{\circ} \mathrm{C}$. Plenum and three walls of the trailing-edge channel were made of $1.27 \mathrm{~cm}$ thick clear acrylic plastic while the fourth wall of the trailing-edge channel, on which a sheet of encapsulated liquid crystals was attached and all measurements were taken, was made of a $12.7 \mathrm{~cm}$ thick machinable polyurethane board with a thermal conductivity of $0.0576 \mathrm{~W} / \mathrm{m}^{\circ} \mathrm{C}$. Three $6.6 \mathrm{~cm} \times 28.2 \mathrm{~cm}$ custom-made etched foil heaters were glued onto the polyurethane wall where measurements were taken. The $0.15 \mathrm{~mm}$ thick etched foil heaters were made of a $0.0127 \mathrm{~mm}$ thick Inconel heating element. The heat spreading foil covered the entire test section with a $0.0127 \mathrm{~mm}$ thick electrically inactive Inconel foil to further spread the heat uniformly over the polyurethane surface. These two Inconel foils were sandwiched and press-glued between three layers of Kapton (custom-made by MINCO). Two polyurethane walls fitting the concave and convex sides were made. They were mounted on the test rig one a time, depending on where the measurements were done.

In the rib-roughened channels, five ribs were mounted on the concave wall with the first one abutting the start of the tilt with a center-to-center pitch of $2.858 \mathrm{~cm}$. On the convex wall, four ribs were mounted in a staggered arrangement with respect to the ribs on the concave wall. Ribs with maximum blockage ratios $\left(e / D_{h}\right)$ of 0.106 and 0.239 , were also made of clear acrylic plastic and made a 90-degree angle with the channel flow direction. Simulating the trailing-edge cooling holes, twenty-two $0.292 \mathrm{~cm}$ diameter holes were drilled on the narrower base of the trapezoidal test section as shown in Figure 1. These holes were $1.27 \mathrm{~cm}$ long and $0.94 \mathrm{~cm}$ apart, and the first hole was at a distance of $0.762 \mathrm{~cm}$ from the start of the tilt. The $7.62 \mathrm{~cm}$ long ribs were tapered from their mid-length to accommodate the tapered trapezoid cross section of the channel. Several flow arrangements for the smooth as well as rib-roughened test sections were tested. These flow arrangements included the total blocking of the trailing-edge holes, that is, an axial flow, a combination of open trailing-edge 


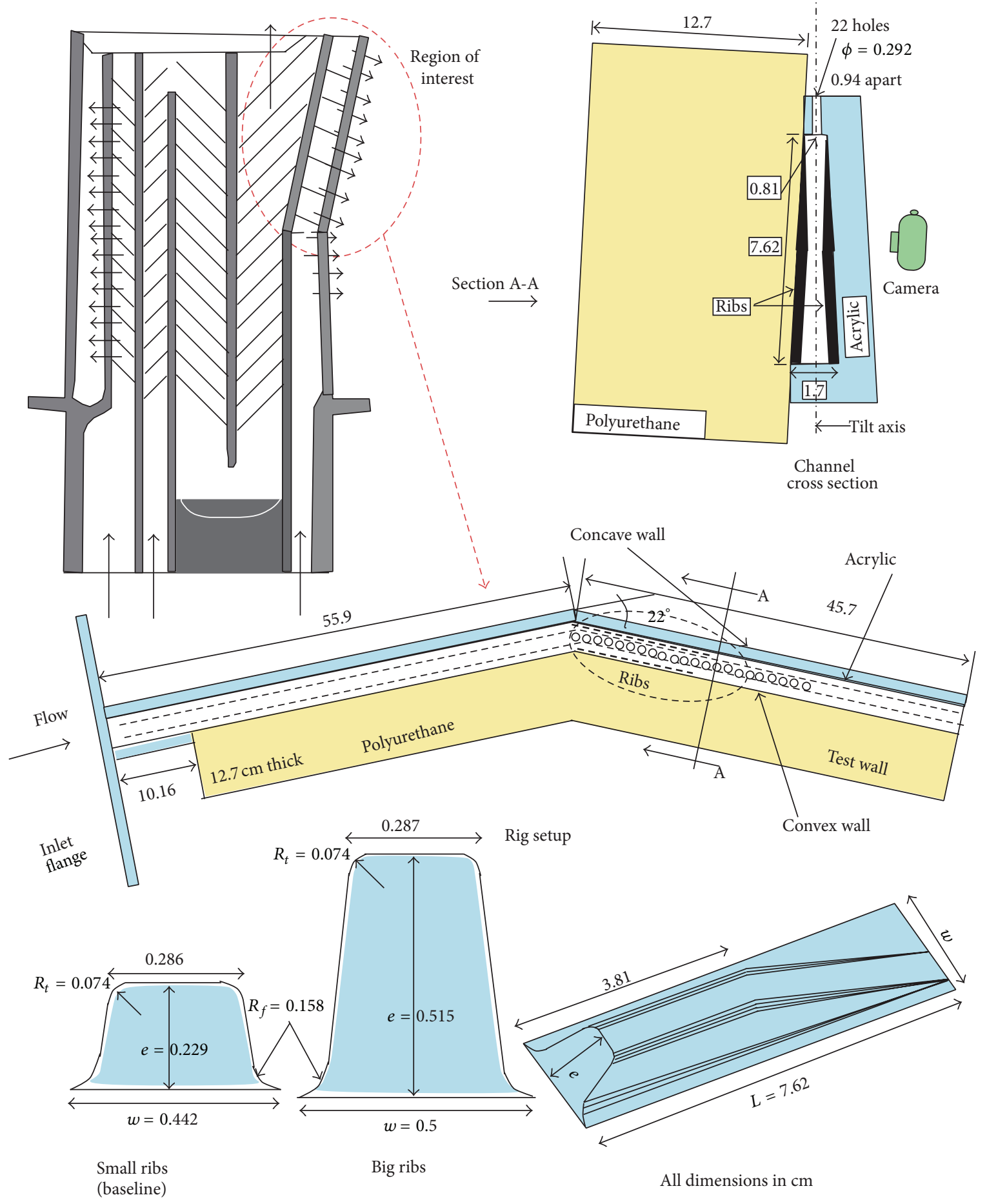

FIGURE 1: Schematics of the rig and the ribs.

holes as well as the channel exit, and two cases of half-closed and completely closed channel exit.

The test sections were covered on all sides, except for a small window at the location where the pictures were taken, with a $5 \mathrm{~cm}$ thick styrofoam slab to minimize heat losses to the environment. The radiation heat loss from the heated wall to the unheated walls as well as losses to ambient air was taken into consideration when heat transfer coefficients were calculated. To accomplish that, the test section was treated as a classic 4-wall enclosure with known surface temperatures. The resulting system of four linear equations for four unknowns, radiosities $\left(J_{1}\right.$ through $\left.J_{4}\right)$, was solved and, from the radiosities, heat flux associated with each surface was evaluated (Ozisik [21]). A digital camera, in conjunction with proper 


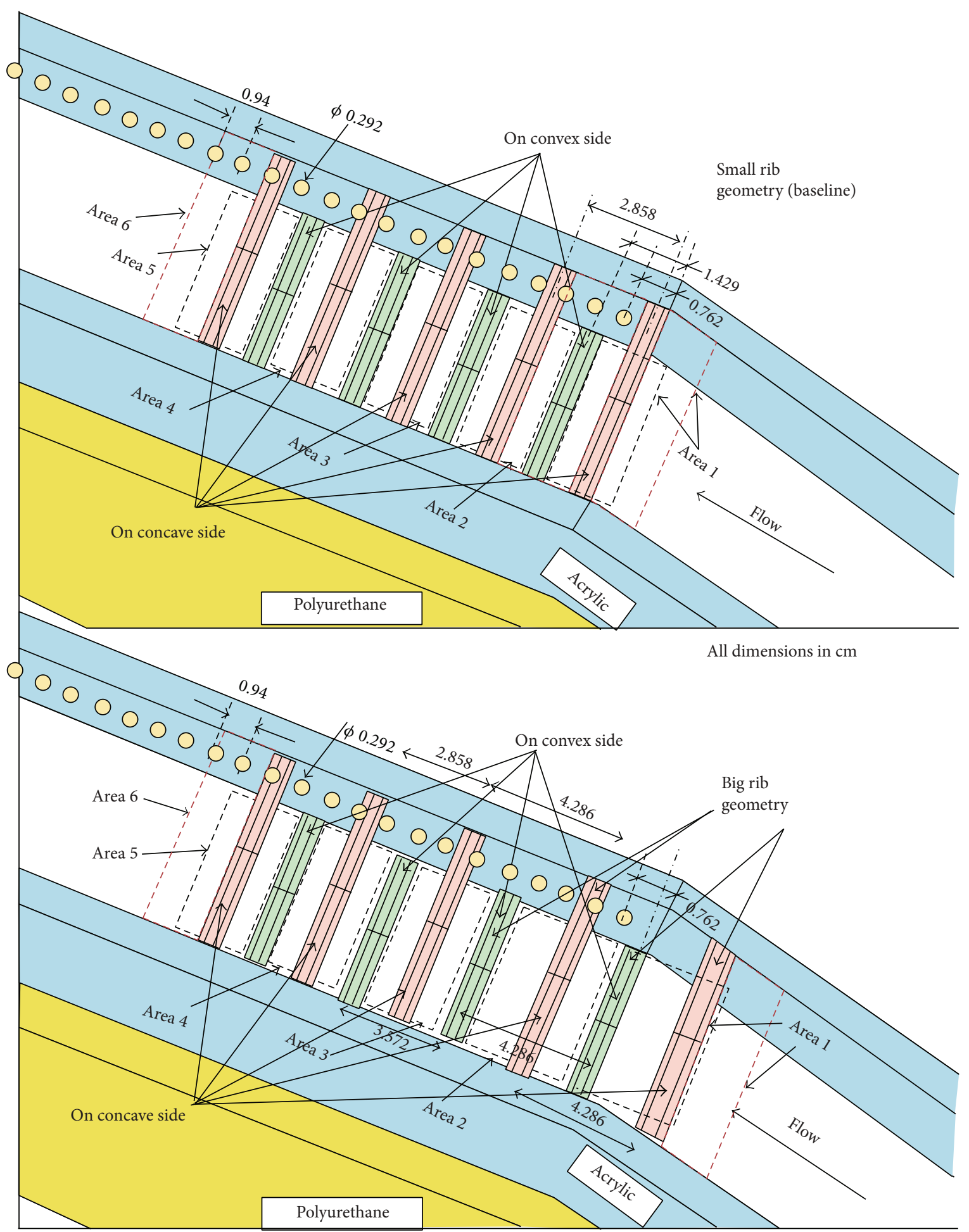

FIGURE 2: Rib arrangements.

filters and background lighting to simulate daylight conditions, was used to take pictures of isochrome patterns formed on the liquid crystal sheet. A centrifugal compressor supplied compressed air to a $0.76 \mathrm{~m}^{3}$ storage tank. A combination of an air dryer and two air filters dried and cleaned the air. A pressure regulator was used to set the air mass flow rate for a desired jet Reynolds number. A critical Venturi, choked for all mass flow rates, was then used to measure the air mass flow rate before it entered the test section plenum at about ambient temperature. Total mass flow rate entering the supply channel 


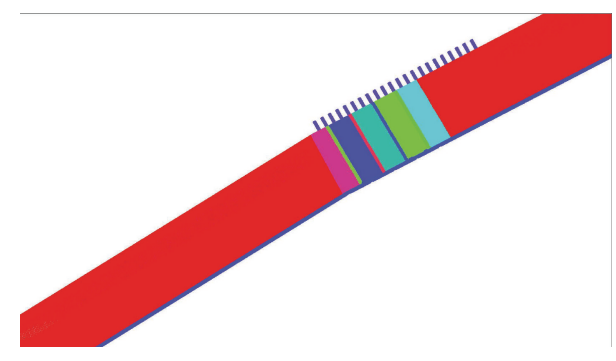

FIGURE 3: View of a typical mesh for the entire domain.

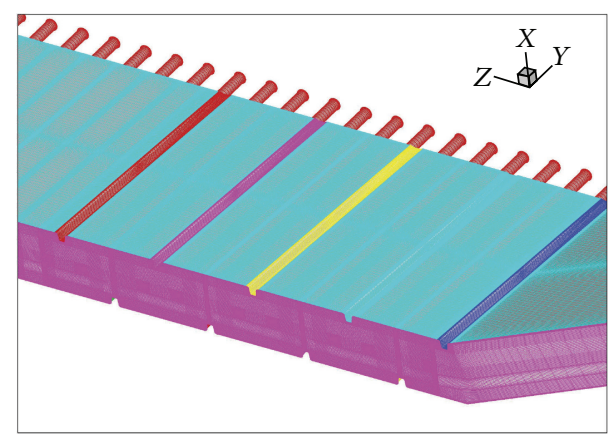

FIGURE 4: Mesh distribution around the rib-roughened section of the channel.

varied from 0.0085 to $0.038 \mathrm{~kg} / \mathrm{s}$. Heat was induced to the air in the test section via the heaters through a custom-designed power supply unit. Each heater was individually controlled by a variable transformer to assure a constant heat flux over the entire heated wall. Two thermocouples measured the air temperature at the channel inlet. Their measurements did not differ by more than a fraction of a degree. A typical inlet temperature was $21^{\circ} \mathrm{C}$. Further details of the rig can be found in Halabi [22].

\section{Computational Model}

The computational model was constructed for the entire setup. The model included the entire rib-roughened trailingedge channel and the 22 trailing-edge holes. Figure 3 shows the mesh for the entire setup while Figure 4 shows the details of the mesh distribution around the rib-roughened section of the channel and the trailing-edge holes. The CFD analyses were performed using Fluent/UNS solver by Ansys, Inc., a pressure-correction based, multiblock, multigrid, unstructured/adaptive solver. Boundary conditions for the numerical models were identical to those of the experiments. At the inlet, a total mass flow rate exactly the same as what was measured $(0.0085-0.038 \mathrm{~kg} / \mathrm{s}$ range) was specified at the same temperature $\left(18-25^{\circ} \mathrm{C}\right.$ range) and pressure (101.35-105.4 KPa range) of the air entering the rig. The heat fluxes on the heated walls were also identical to those of experiment (2500$4000 \mathrm{~W} / \mathrm{m}^{2}$ range).

Trailing-edge holes and channel exit had a pressure boundary condition identical to that of the lab. The realizable $k-\varepsilon$ turbulence model in combination with enhanced wall treatment approach for the near wall regions was used for turbulence closure (Fluent, Theory, Chapter 4). The average $y^{+}$for the first layer of cells was calculated to be below 5 for all cases since the enhanced wall treatment method was employed. Other available turbulence models in this commercial code including the $\kappa-\omega$ with shear stress transport (SST) option and $v 2 f$ models were also tested and the corresponding results are compared. Mesh independence was achieved at about 15 million cells for a typical model. For a representative geometry, the heat transfer results of a series of meshed models with different number of elements were compared. As the mesh became more and more refined, the heat transfer results came closer and closer to each other. When a difference of a fraction of a percent between two consecutive meshes was observed, no further refinement was done. We reached that situation when the total number of elements was about $15 \mathrm{M}$. We started at $8 \mathrm{M}$ and increased the element numbers by about $2 \mathrm{M}$ at a time first and $1 \mathrm{M}$ at the end. Cells in all models were entirely hexagonal, a preferred choice for CFD analyses, and were varied in size bigeometrically from the boundaries to the center of the computational domain in order to have finer mesh close to the boundaries. Residual sums for all variables in all models were less than 1 $\times 10^{-7}$. Convergence, for most cases, was achieved at around 15,000 iterations.

\section{Results and Discussion}

Experimental and numerical results are presented for the section of the channel around the 22-degree tilt for smooth as well as rib-roughened geometries and four flow arrangements which was mentioned earlier. Measurements were performed both on the convex wall (Areas 1 through 5 in Figure 1) and on the concave wall (Areas 1 through 6) which covered the portion of the airfoil cooling cavity affected by the passage tilt. Area 1 on both walls is upstream of the first rib while Areas 5 on the convex wall and 6 on the concave wall are immediately downstream of the last rib. Local area-weighted average Nusselt numbers are reported as a function of the local Reynolds number. To determine the percentage of the total flow through individual trailing-edge holes, thorough analyses of the flow fields for different flow arrangements had to be done. A three-dimensional CFD model of each flow arrangement was run under the tests boundary conditions.

Figure 5 shows the percentage of total mass flow rate passing through the trailing-edge holes for the smooth and rib-roughened geometries. It is defined as the mass flow of air through each individual hole divided by the total mass measured at the channel inlet, multiplied by 100 . This graph was generated from the CFD results. Several observations are made. The smooth test section, represented by the solid symbols, shows a slight overall decrease in the flow direction for each inlet Reynolds number. This is supported by the contours of velocity magnitude presented in Figure 6 which shows a repeating pattern for all trailing-edge holes. Also, it is noticed that, for both smooth and rib-roughened cases, there is a slight decrease in the percentage of mass flow rate through each hole as the Reynolds number (total mass flow) increases. This is explained by the higher axial flow inertia at higher Reynolds numbers weakening the lateral flow towards 


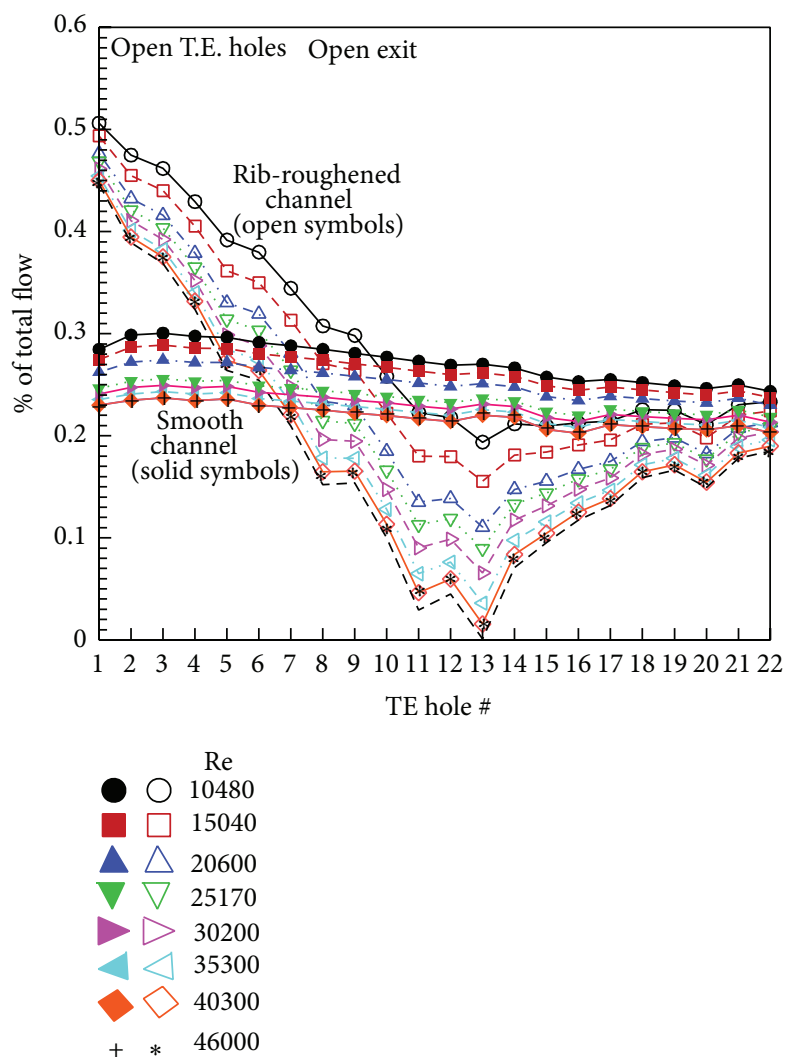

FIGURE 5: Percentage of mass flow rate through the trailing-edge holes in the smooth and rib-roughened channels.

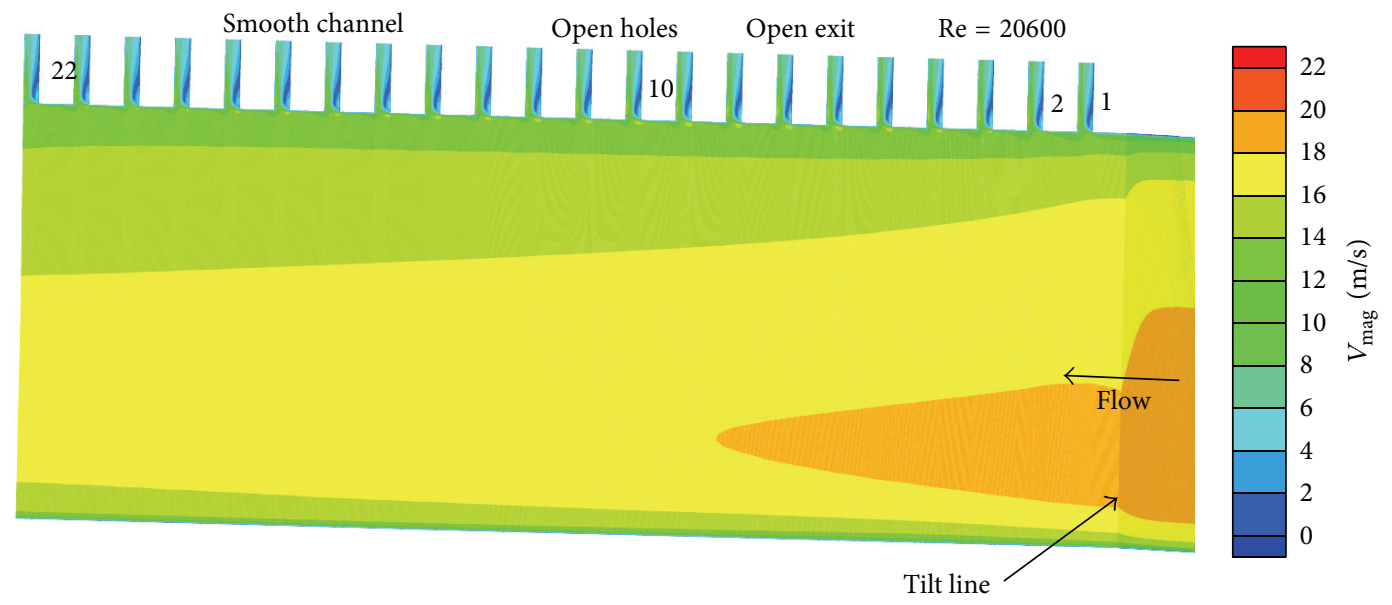

FIGURE 6: CFD contours of the velocity magnitudes on the channel mid-plane downstream the 22-degree tilt for the smooth wall case, open trailing-edge holes, and open channel exit.

the trailing-edge holes. The case of rib-roughened channel is different. The first hole, at the beginning of the rib-roughened section, has the maximum percentage. Sudden blockage of the channel by the ribs as well as the tilt of the passage is the cause of stronger lateral flow for the holes 1 through 9. The decreasing trend brings the flow percentage to a minimum around the hole number 13 which is at about the end of the rib-roughened section. As the flow departs the rib-roughened section, the mass flow percentages pick up until they reach the smooth geometry rates again. Figure 7 shows the contours of velocity magnitude on the channel mid-plane for a representative case of rib-roughened geometry. Changes in flow structure and formation of a lateral flow towards the trailing-edge holes are evident. The effects of the changes in flow structure, due to the presence of the ribs, on the mass flow rates through the trailing-edge holes and on the heat transfer coefficients 


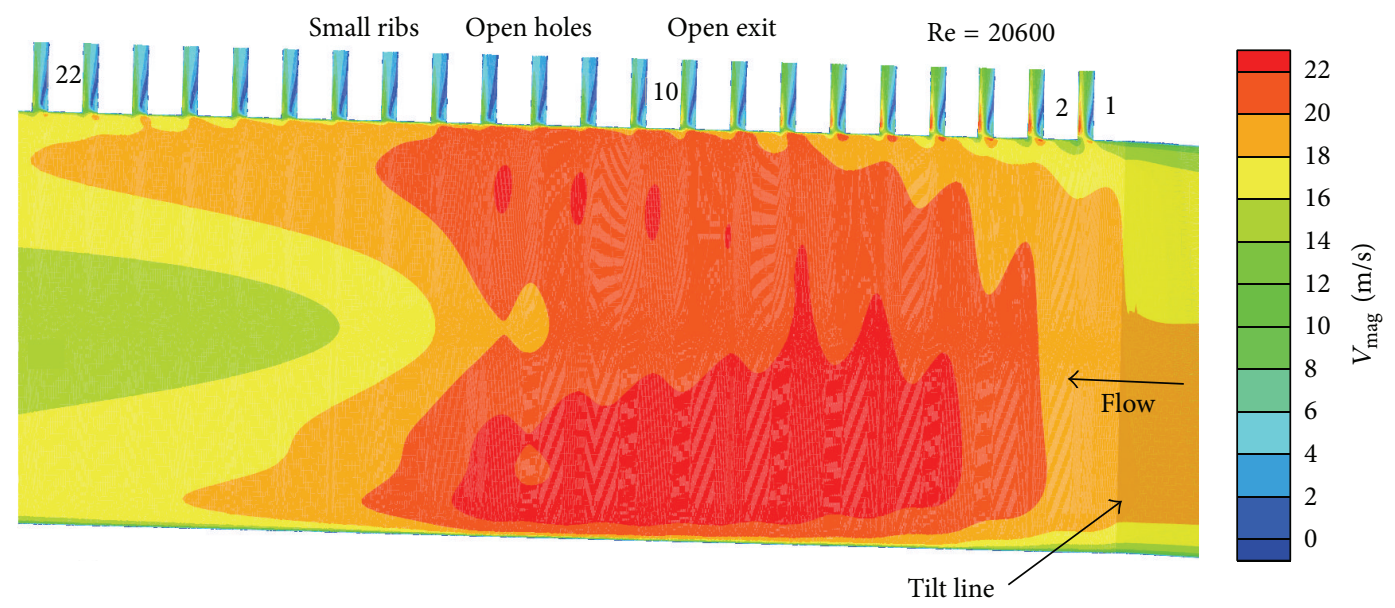

FIGURE 7: CFD contours of the velocity magnitudes on the channel mid-plane downstream the 22-degree tilt for the small ribs, open trailingedge holes, and open channel exit.

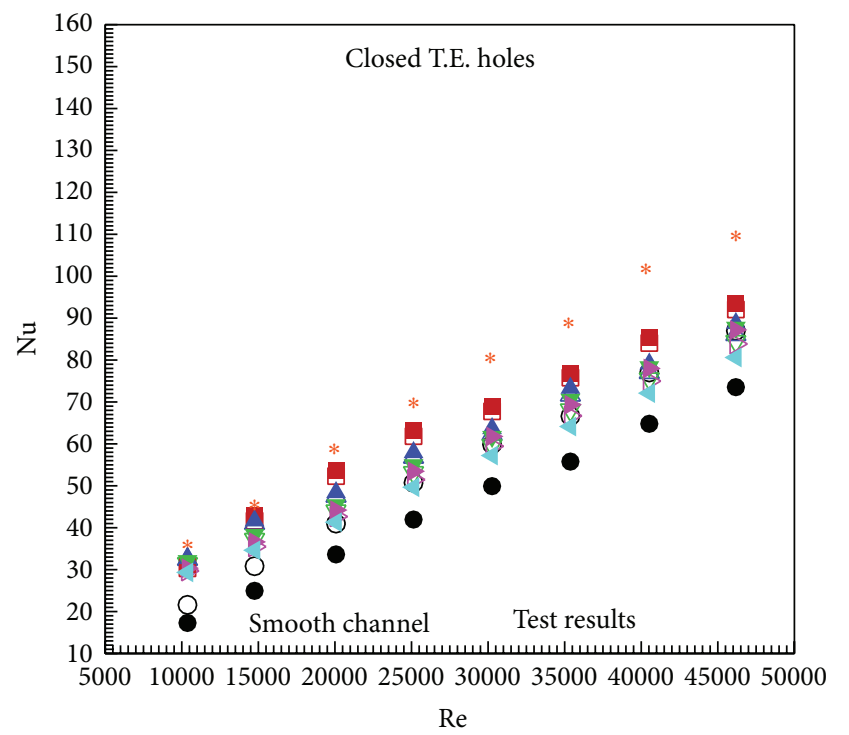

\begin{tabular}{|c|c|}
\hline $\begin{array}{c}\text { Convex side } \\
\text { Area }\end{array}$ & $\begin{array}{c}\text { Concave side } \\
\text { Area }\end{array}$ \\
\hline$\bigcirc \quad 1$ & - 1 \\
\hline$\square \quad 2$ & 口 2 \\
\hline$\triangle 3$ & $\triangle 3$ \\
\hline$\nabla \quad 4$ & $\nabla \quad 4$ \\
\hline$\triangleright \quad 5$ & $>5$ \\
\hline * Dittus-Boelter & 46 \\
\hline
\end{tabular}

FIGURE 8: Measured heat transfer results in the smooth channel on the convex and concave walls for the case of closed trailing-edge holes and open channel exit.

on the rib-roughened walls will be discussed in the ensuing sections. It should be noted that the case of closed channel end produced equal flow percentages for all 22 holes (4.55\%) due to pressure buildup inside the channel that acted like a high pressure plenum and sent the same amount of flow through each trailing-edge hole.
The heat transfer coefficient corresponding to each recorded picture of liquid crystals display was calculated from

$$
h=\frac{q^{\prime \prime}-q_{b}^{\prime \prime}-q_{r}^{\prime \prime}}{T_{s}-T_{m}}
$$

where $T_{s}$ and $T_{m}$ are the surface and local air mixed mean temperatures, respectively. The mixed mean temperature is calculated by applying an energy balance from the test section inlet to the point in question. $q^{\prime \prime}$ is the total heat flux generated by the foil heater, $q_{b}^{\prime \prime}$ is the total heat loss through the back of the channel wall to the ambient, and $q_{r}^{\prime \prime}$ is the total radiation losses from the heated channel wall to the surrounding unheated walls. Air properties including the viscosity and thermal conductivity for the calculation of the local Reynolds and Nusselt numbers were evaluated at the local film temperature. Experimental uncertainties in Reynolds numbers, friction factor, and heat transfer coefficients, following the method of Kline and McClintock [23], were calculated to be about $\pm 3 \%, \pm 3 \%$, and $\pm 6 \%$, respectively (individual uncertainties: $\delta T=0.3^{\circ} \mathrm{C}, \delta v=0.1$ volt, $\delta i=0.01 \mathrm{amp}$, $\delta A_{\text {heater }}=2.54 \times 10^{-6} \mathrm{~m}^{2}$, and $\delta(\Delta P)=2.54 \times 10^{-5} \mathrm{~m}$ of water column). Results of the smooth channel will be discussed first, followed by the rib-roughened cases.

4.1. Smooth Channel. Test results for the smooth channel when the trailing-edge holes were closed and flow emerged through the channel exit are shown in Figure 8 on the convex and concave walls. Areas 1 through 5 are on the convex wall immediately after the tilt and Areas 1 through 6 are on the concave wall in the same region. Areas 1 on both the concave and convex walls are located immediately after the channel tilt and they both represent a lower heat transfer coefficient than the remaining areas. This is explained by Figure 9 which shows the CFD contours of the velocity magnitude around the tilted region. It is seen that Area 1 on the concave wall does not benefit from the cooling flow as much as Area 1 on the convex wall does. Since the channel cross section is tapered 


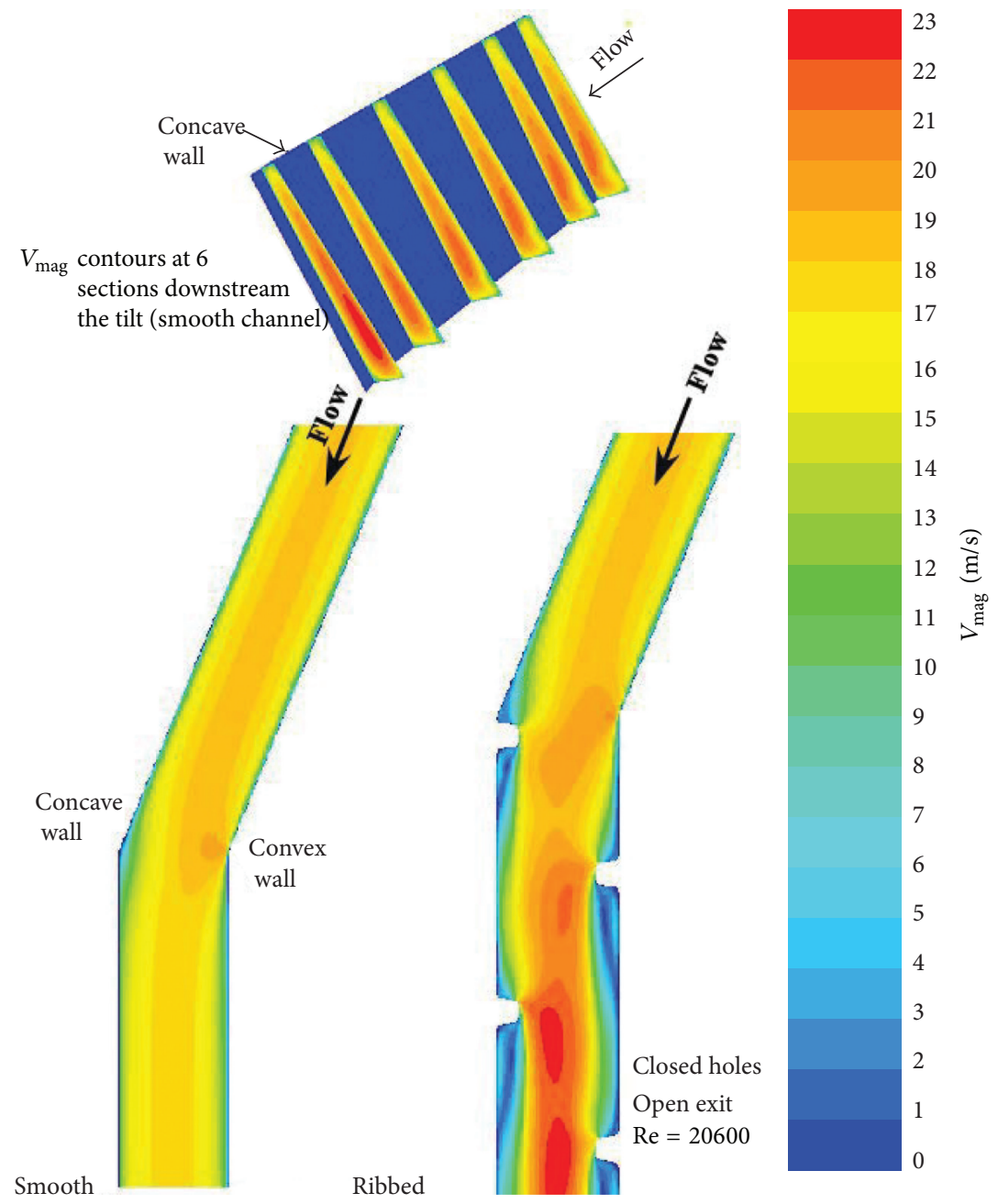

FIGURE 9: Velocity magnitude contours on the mid-plane around the channel tilt (bottom) and on six sections downstream the tilt (top) for the case of closed trailing-edge holes and open exit.

(trapezoidal), most of the flow moves towards the wider end of the test section. Thus the flow departs from the concave wall, moves towards the convex wall, and rubs against that surface. The end result is the low heat transfer coefficient on the concave wall. As the flow reestablishes, there is a gradual increase of heat transfer coefficient in the flow direction. Dittus-Boelter correlation results for the turbulent flow in a straight channel are also shown on this figure to confirm a net deficit in heat transfer coefficient around the tilt in a smooth channel. In Figure 10, the CFD results of the same case, shown by the lines, are compared with the test results. The CFD results, although generally in reasonable agreement with the test results, seem to overpredict, especially on Areas 1 immediately after the tilt. However, for other areas, the agreement is much better.

4.2. Small Ribs. Figure 11 shows the test results for the ribroughened channel with the small ribs when the trailing-edge holes were closed and flow emerged only through the channel exit. Heat transfer results are shown both on the convex and concave walls. Again, Areas 1 on both the concave and convex walls, located immediately after the channel tilt, represent a lower heat transfer coefficient than the remaining areas. This is explained by Figures 9 and 12 which show the CFD contours of the velocity magnitude around the tilted region. It is seen that Area 1 on the concave wall does not benefit from the cooling flow as much as Area 1 on the convex wall does. The cooling air skips the first rib on the concave wall and moves towards the convex wall of the test section. The end result is the low heat transfer coefficient on the concave wall. As the flow reestablishes, there is a gradual increase of heat transfer coefficient in the flow direction. CFD results of the same case, shown by the lines, are compared with the test results. Again, the CFD results, although generally in reasonable agreement with the test results, seem to overpredict, especially on Areas 1 immediately after the tilt. However, for other areas, the agreement is much better.

Figure 13 shows the test results for the rib-roughened channel with the small ribs when both the trailing-edge holes and channel exit were open. Heat transfer results are shown both on the convex and concave walls. Again, Areas 1 on both the concave and convex walls, located immediately after the 


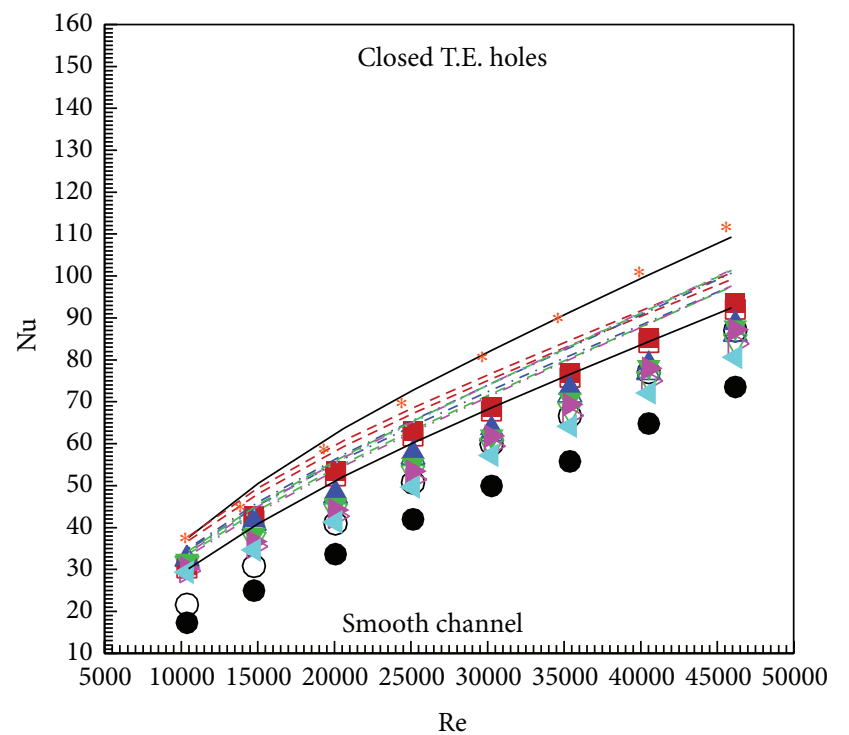

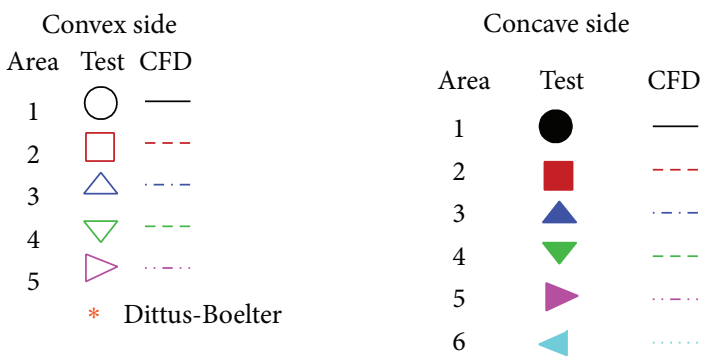

FIGURE 10: Comparison of the measured and CFD heat transfer results in the smooth channel on the convex and concave walls for the case of closed trailing-edge hole.

channel tilt, represent a lower heat transfer coefficient than the remaining areas. However, heat transfer coefficients on the concave wall are higher than those on the convex wall. This is explained by the formation of the lateral flow towards the trailing-edge holes that have increased the interaction between the cooling flow and the concave wall. This is evidenced by Figures 14 and 15 that show the temperature and Nusselt number on the rib-roughened wall. Regions of low surface temperature and high Nusselt numbers are close to the opening of the trailing-edge holes. Furthermore, gradual increase on the Nusselt number in the flow direction is observed.

Test results for the two rib geometries and under three different flow arrangements are shown in Figures 16, 17, and 18. Figure 16 corresponds to the case of closed trailing-edge holes and open channel exit. Figure 17 corresponds to the case of open trailing-edge holes and only half-open channel exit. A $1.37 \mathrm{~cm}$ thick trapezoidal acrylic plate with a circular hole in the middle blocked the channel exit. The circular opening representing a tip hole in the trailing-edge cooling cavity of an airfoil had exactly half of the area of the trapezoidal cross section. The flow distribution through the bleed holes and channel exit was $24 \%$ and $76 \%$, respectively. Figure 18 corresponds to the case of open trailing-edge holes and totally blocked

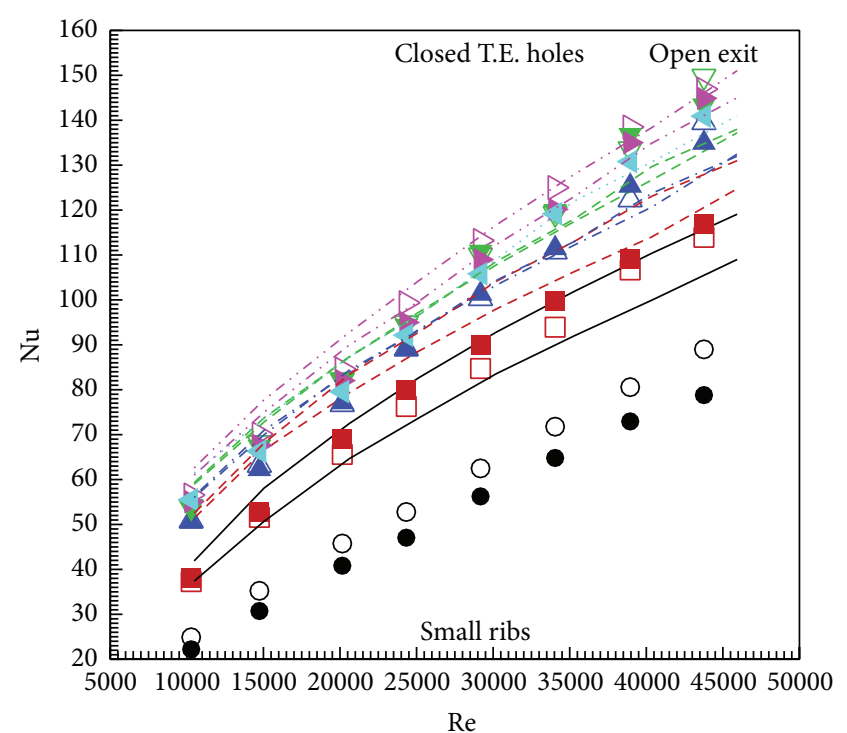

Convex side

Area Test CFD

$\begin{array}{lll}1 & \bigcirc & - \\ 2 & \square & --- \\ 3 & \triangle & \cdot \cdot- \\ 4 & \nabla & --\cdot \\ 5 & \triangleright & \cdots-\cdot\end{array}$

Concave side

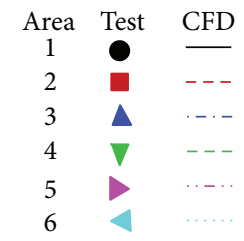

Figure 11: Comparison of the measured and CFD heat transfer results in the rib-roughened channel on the convex and concave walls for the case of closed trailing-edge hole and open channel exit.

channel exit. Again, Area 1 had the lowest heat transfer coefficient and as the flow established itself downstream the tilt, the difference in heat transfer coefficients on the consecutive areas became small. Please note that, as shown in Figure 2 (bottom sketch), the first bigger rib was installed before the tilt in order to increase the heat transfer coefficient immediately after the tilt. The increased blockage accelerated the follow downstream the tilt and produced the maximum heat transfer coefficient on the 3rd area. A comparison of Figures 16 and 10 shows that the ribs in the presence of the tilt still effectively enhance the heat transfer coefficients. Of particular interest is the case of blocked channel exit. A pressure buildup in the channel only allowed for a maximum mass flow rate corresponding to a maximum Reynolds number of about 18,000 . In all these three cases, bigger ribs produced much higher heat transfer coefficients as expected.

As was mentioned earlier, several turbulence models including the $\kappa-\varepsilon, \kappa-\omega$, and $v 2 f$ models were used for all numerical cases and results for different geometries were compared. It was then concluded that the realizable $\kappa-\varepsilon$ turbulence model in combination with enhanced wall treatment approach for the near wall regions with the second order upwind discretization produced, for most cases, the closest heat transfer results to the measured data. Figure 19 compares the numerical and tested results for one representative case of open trailing-edge, open channel exit arrangement, and 


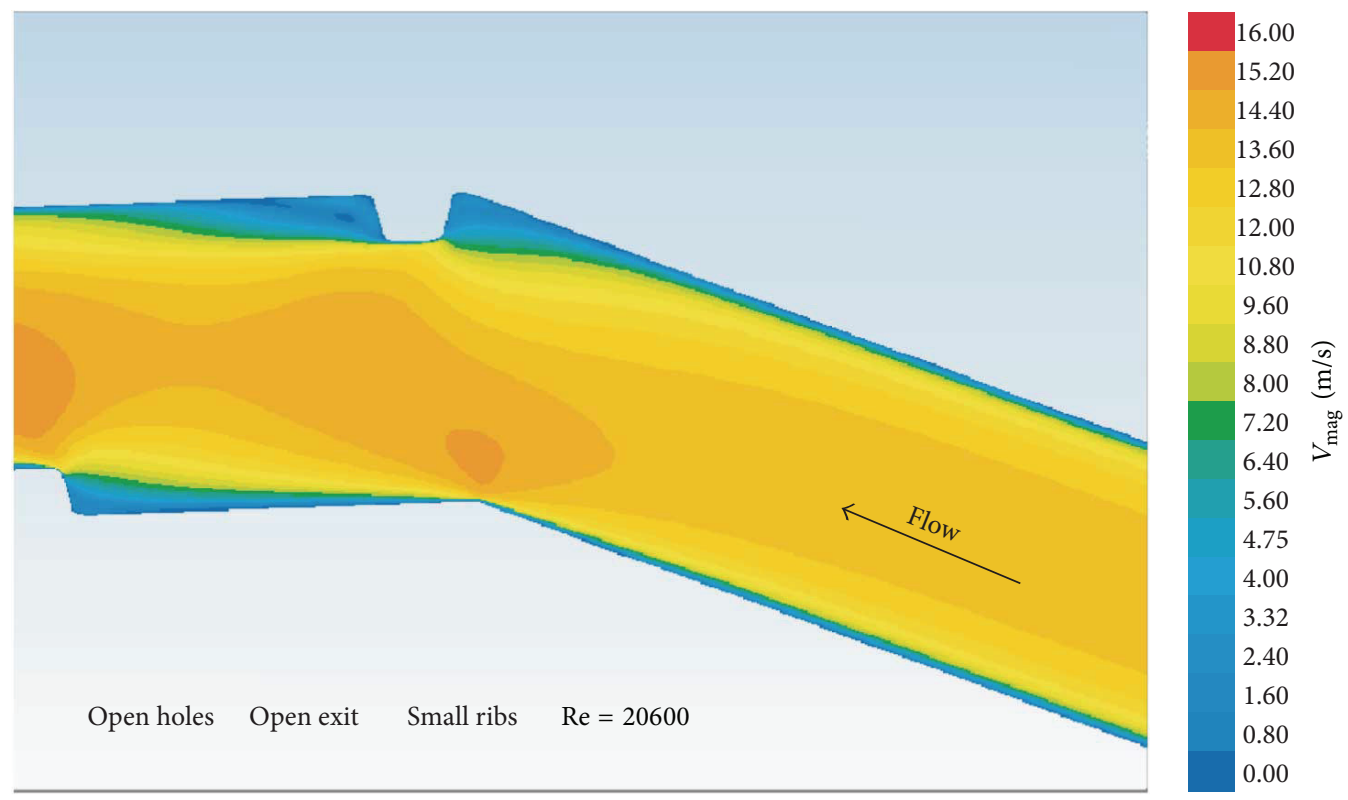

FIGURE 12: Velocity magnitude contours around the channel tilt for the case of open trailing-edge holes and open exit with small ribs.

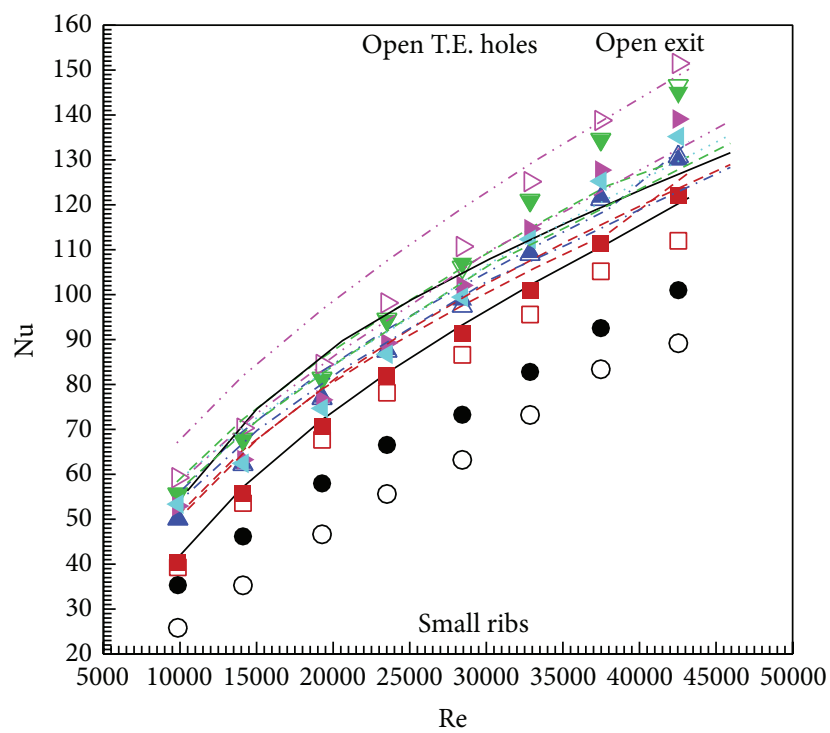

\begin{tabular}{ccc}
\multicolumn{4}{c}{ Convex side } \\
Area & Test & CFD \\
1 & $\bigcirc$ & - \\
2 & $\square$ & --- \\
3 & $\triangle$ & $-\cdot-$ \\
4 & $\nabla$ & $-\cdot-$ \\
5 & $\triangleright$ & $\cdots-\cdot$
\end{tabular}

\begin{tabular}{ccc}
\multicolumn{3}{c}{ Concave side } \\
Area & Test & CFD \\
1 & - & - \\
2 & $\square$ & --- \\
3 & $\mathbf{D}$ & $-\cdot-$ \\
4 & $\nabla$ & $--\cdot$ \\
5 & & $\cdots$ \\
6 & 4 & $\cdots$
\end{tabular}

FIGURE 13: Comparison of the measured and CFD heat transfer results in the rib-roughened channel on the convex and concave walls for the case of open trailing-edge holes and open channel exit. 


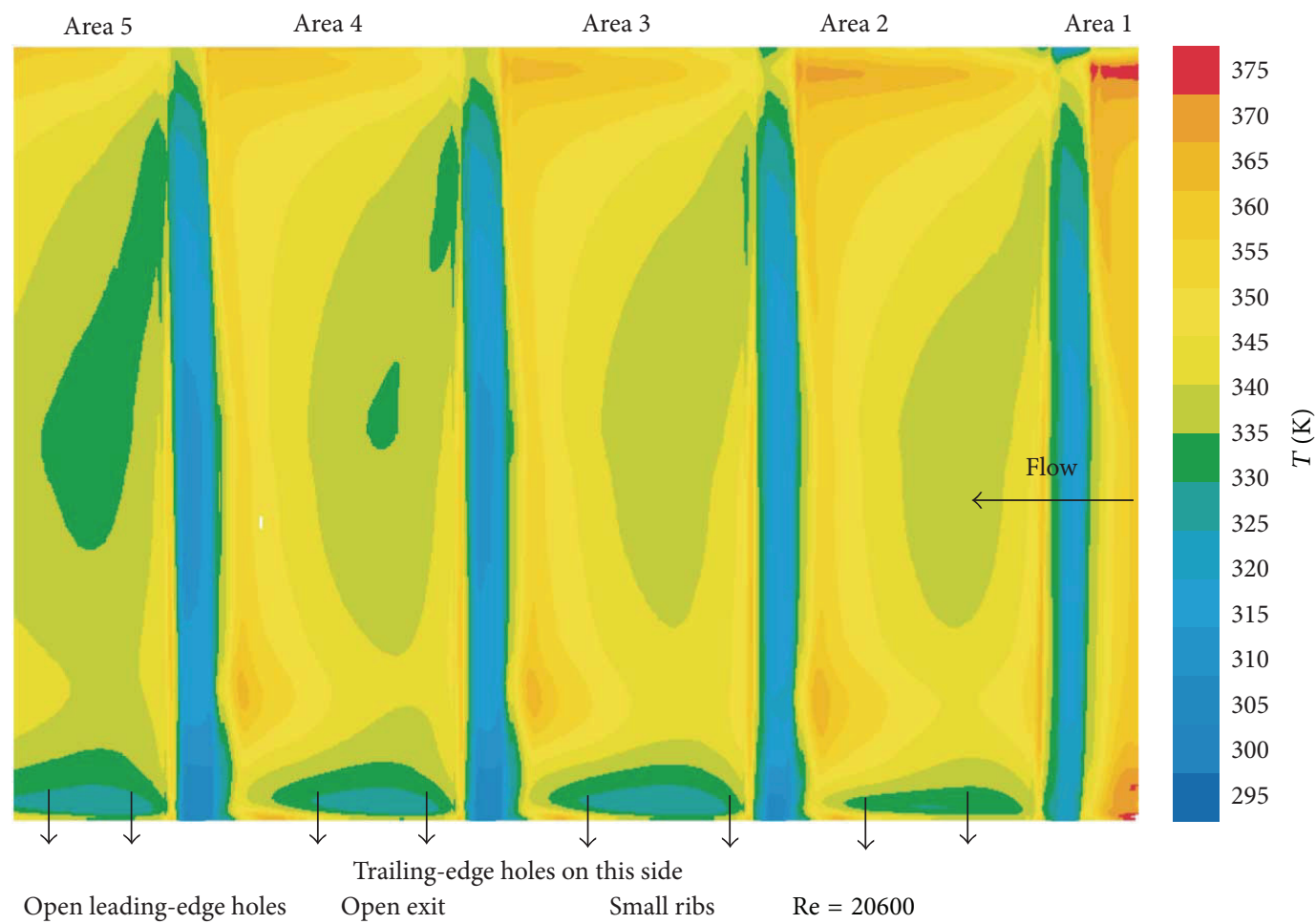

FIGURE 14: Contours of surface temperature on Areas 2 through 5 on the concave wall, open trailing-edge holes, open exit, small ribs.

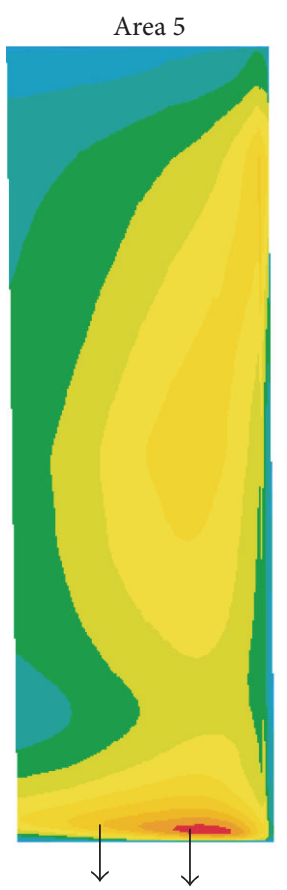

Open trailing-edge holes

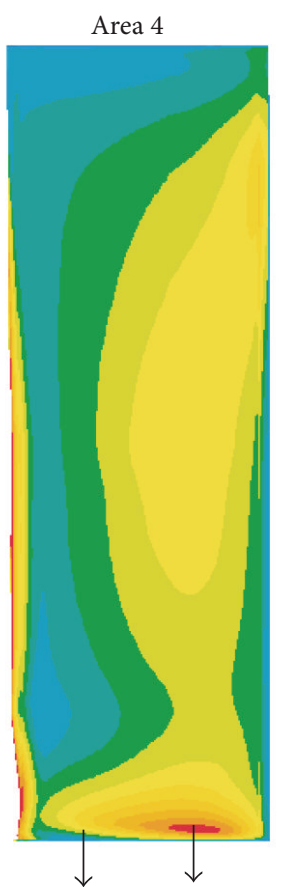

Area 3

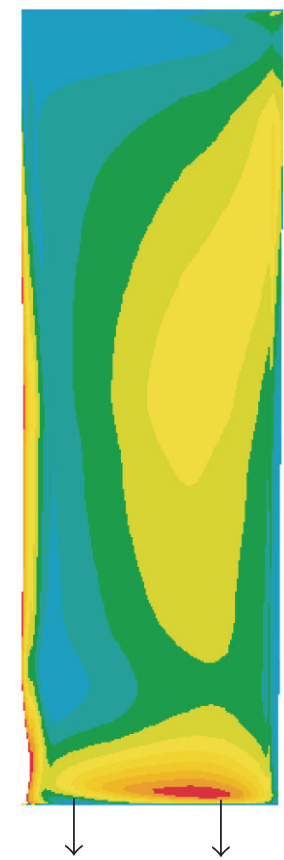

Trailing-edge holes on this side

Open exit $\quad \operatorname{Re}=20600$

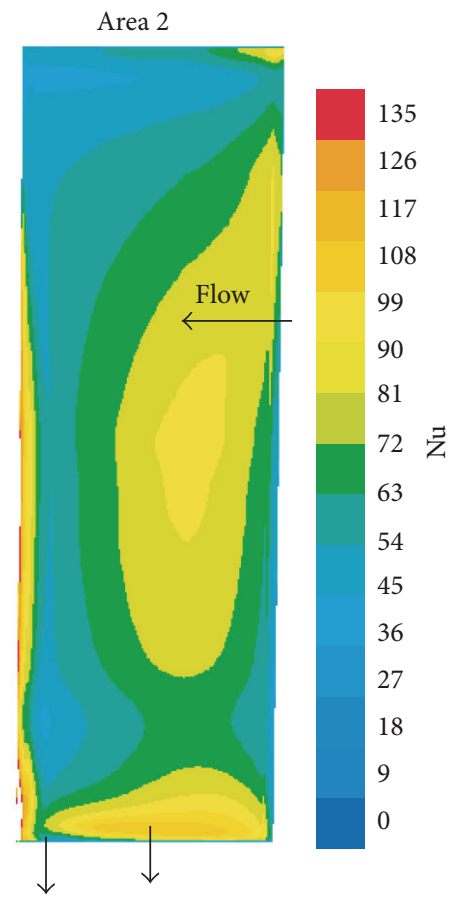

2 㝋

3

54

5

36

27 (1)

FIGURE 15: Contours of Nusselt number on Areas 2 through 5 on the concave wall, open trailing-edge holes, open exit, small ribs.

small ribs. The superiority of the $k-\varepsilon$ model over the two other models is evident. Numerical results for other geometries and flow arrangements produced the same trend and are not presented here due to space limitation.
Finally, measured Darcy friction factors for all tested geometries and flow arrangements are shown in Figure 20. The cluster of solid symbols on the upper side of the graph corresponds to the big ribs. Hollow symbols on the lower side 


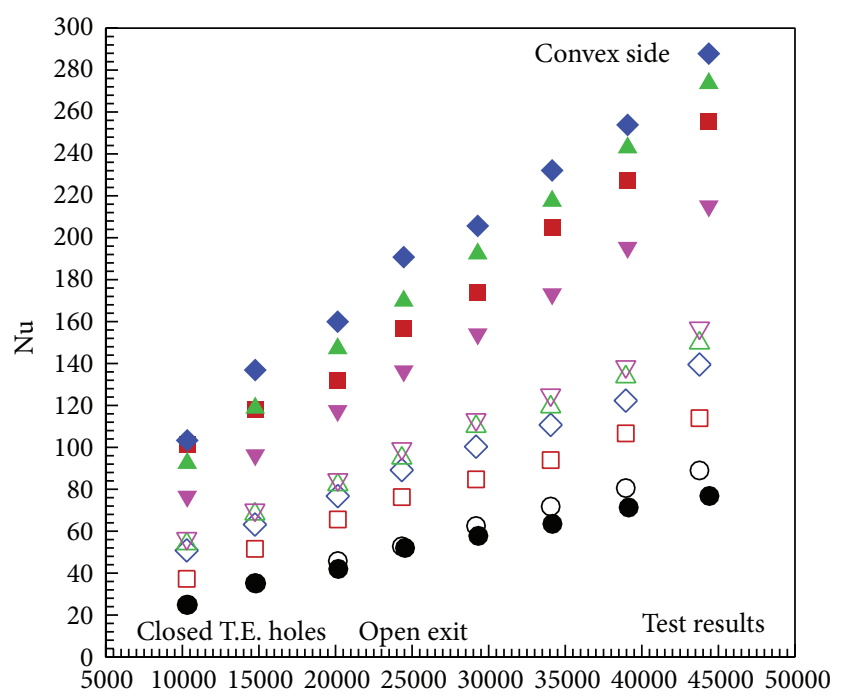

$\operatorname{Re}$

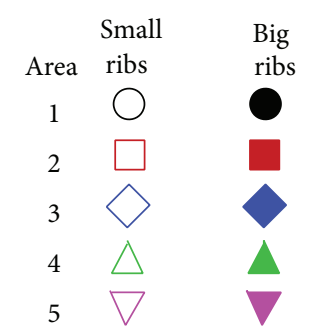

FIGURE 16: Measured Nusselt number variation with Reynolds number on all areas on the convex wall for the two rib geometries, closed trailing-edge holes, and open channel exit.

represent the cases of small ribs and smooth channel. CFD results for four geometries are also shown by solid and dashed lines. As expected, based on our previous work, they are in very good agreement with the test results. Of particular interest is the case of closed channel exit in which the flow decelerates in the axial direction due to air bleed through the trailingedge holes and, as a result, the static pressure increases. In the case of small ribs, the pressure drop due to the presence of the ribs is not large enough to produce an overall decrease of pressure along the channel. That is the reason for the negative friction factor. In the case of big ribs, however, pressure drop due to the presence of big ribs is more than the pressure gain due to flow deceleration. The end result is a net pressure drop that results in a small positive friction factor.

\section{Conclusions}

A heat transfer and pressure drop study was performed in a tilted trailing-edge channel with and without the presence of ribs. Major conclusions of this study are as follows.

(1) In the smooth channel, there was a decrease in heat transfer coefficient on the area immediately after the tilt, followed by a gradual increase in heat transfer coefficient in the flow direction until the flow reestablished itself to a straight channel flow. Both on the

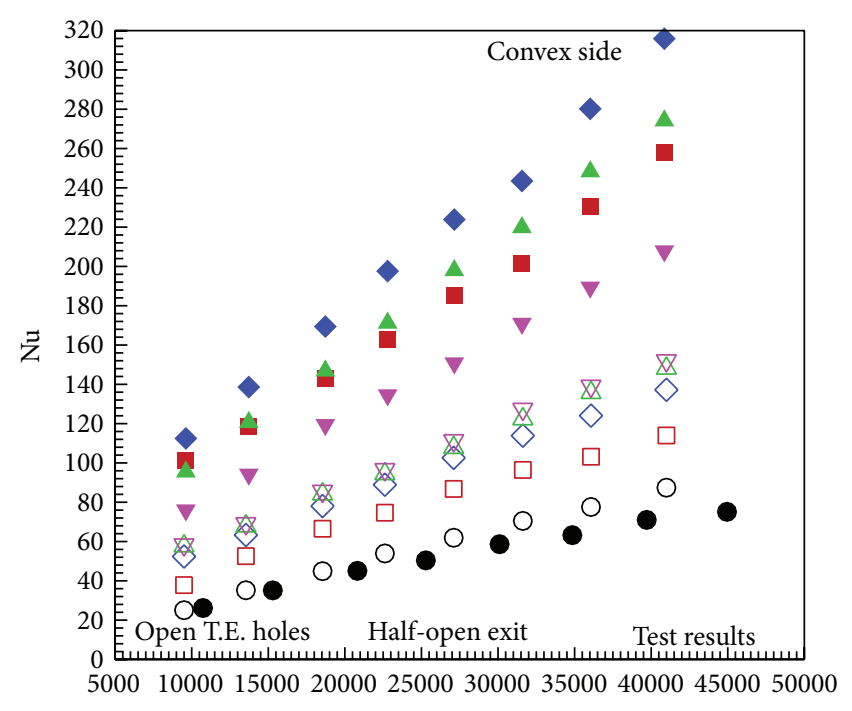

$\operatorname{Re}$

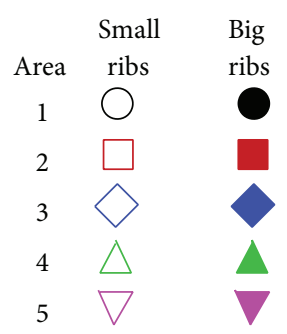

FIGURE 17: Measured Nusselt number variation with the local Reynolds number on all areas on the convex wall for the two rib geometries, open trailing-edge holes, and 1/2 blocked channel exit.

convex and concave walls, the measured heat transfer coefficients remained below the straight channel (Dittus-Boelter) levels.

(2) The rib-roughened cases, except for the areas upstream the first ribs on the convex and concave walls, were less affected by the tilt.

(3) Numerical heat transfer results with the use of the realizable $\kappa-\varepsilon$ turbulence model in combination with enhanced wall treatment approach for the near wall regions were generally in a reasonable agreement with the test results. The maximum difference between the CFD and test results was about $20 \%$. We attribute the difference to CFD shortcomings.

\section{Nomenclatures}

$A_{\text {heater }}$ : Foil heater area, $\left[\mathrm{m}^{2}\right]$

AR: $\quad$ Trailing-edge channel aspect ratio, $\left(b_{\min }+b_{\max }\right) / 2 H=0.165$

$b_{\max }: \quad$ Test section maximum base, $1.7 \mathrm{~cm}$

$b_{\min }$ : Test section minimum base, $0.81 \mathrm{~cm}$

$D_{h}$ : Trailing-edge channel hydraulic diameter, $2.155 \mathrm{~cm}$

$d: \quad$ Trailing-edge hole diameter, $0.292 \mathrm{~cm}$

$e$ : $\quad$ Rib maximum height, 0.229 and $0.515 \mathrm{~cm}$ 


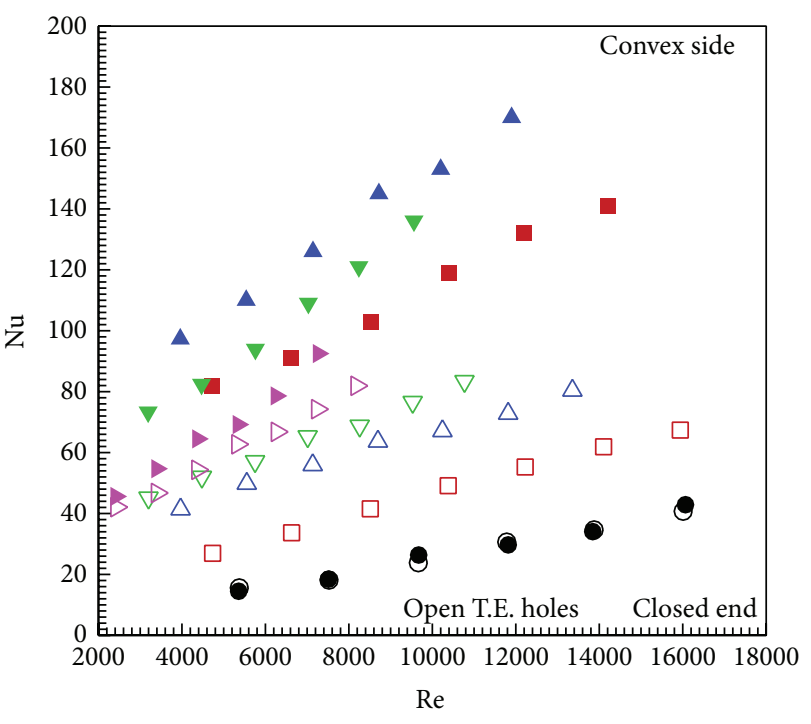

$$
\begin{array}{ccl}
\text { Small } & & \text { Big } \\
\text { ribs } & \text { Area } & \text { ribs } \\
\bigcirc & 1 & \\
\square & 2 & \square \\
\triangle & 3 & \Delta \\
\nabla & 4 & \nabla \\
\triangleright & 5 & \nabla
\end{array}
$$

FIGURE 18: Measured Nusselt number variation with the local Reynolds number on all areas on the convex wall for the two rib geometries, open trailing-edge holes, and closed channel exit.

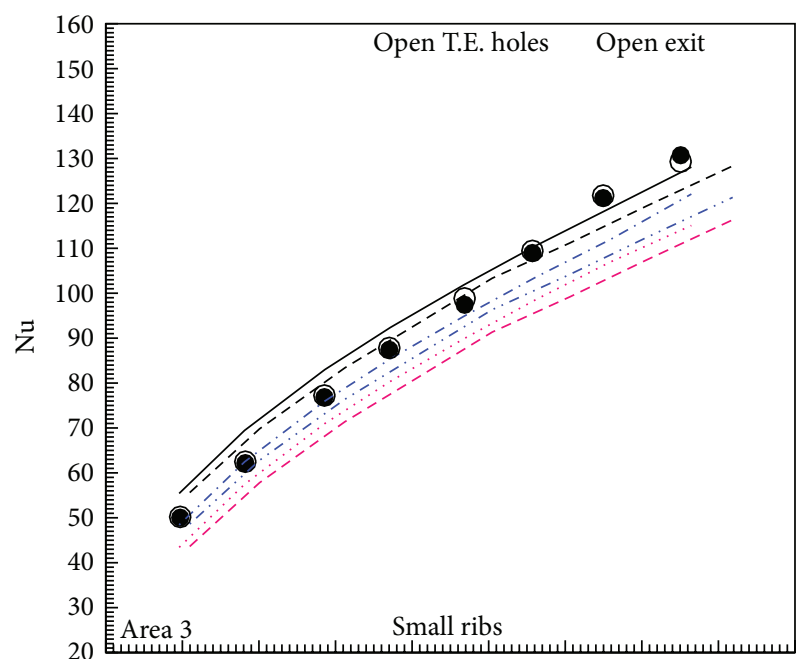

5000100001500020000250003000035000400004500050000

$\operatorname{Re}$

\begin{tabular}{|c|c|}
\hline Convex side & Concave side \\
\hline Test $\bigcirc$ & Test \\
\hline$k-e$ & $k-e-$ \\
\hline$k-w \ldots \ldots$ & $k-w$ \\
\hline v2f $\ldots$ & v2f $\quad--$ \\
\hline
\end{tabular}

Figure 19: Comparison of the $\kappa-\varepsilon, \kappa-\omega$, and $v 2 f$ turbulence models with the test results on the convex and concave walls (Area 3 ) for the case of open trailing-edge holes and open exit with small ribs.

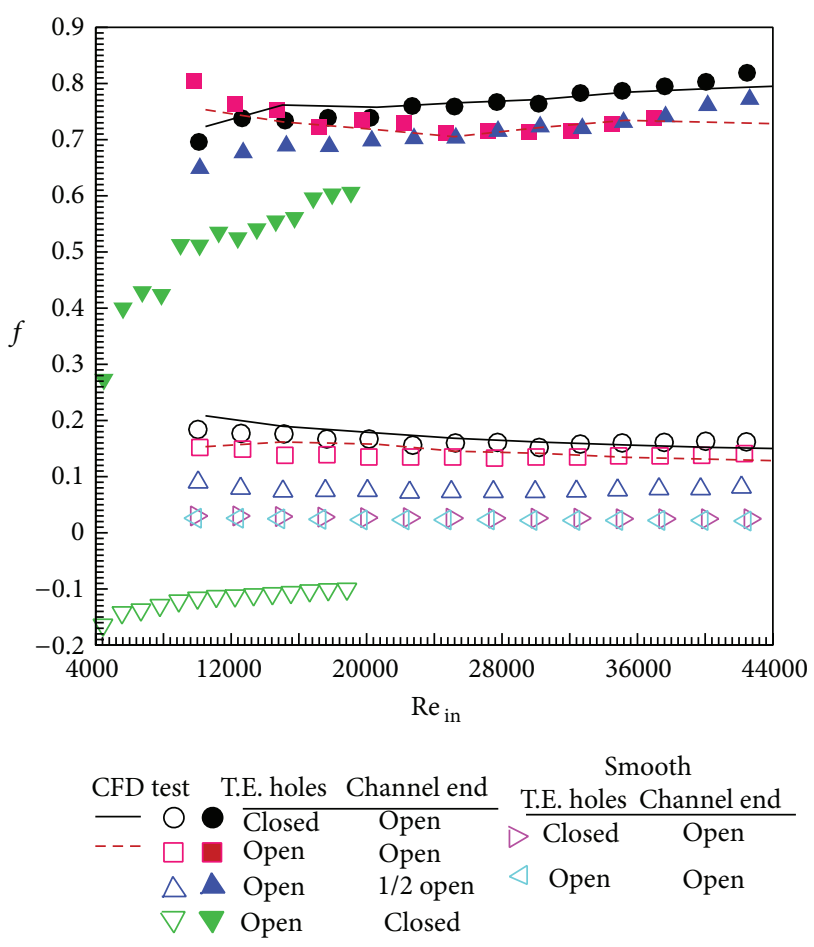

FIgURE 20: Darcy friction factor variation for all tested geometries.

$f: \quad$ Darcy friction factor $=$ $2 \Delta P\left(D_{h} / L_{\text {ribbed }}\right) \rho V^{2}$

$h$ : $\quad$ Heat transfer coefficient, $\left[\mathrm{W} / \mathrm{m}^{2 \circ} \mathrm{C}\right]$

$H: \quad$ Test section height, $7.61 \mathrm{~cm}$ (Figure 1)

$i$ : Current through the surface foil heater, [amps]

$k$ : $\quad$ Air thermal conductivity, $\left[\mathrm{W} / \mathrm{m}^{\circ} \mathrm{C}\right]$

$L_{\text {ribbed }}$ : Rib-roughened length of the channel, $[L]$

$m$ : Local air mass flow rate, $[\mathrm{Kg} / \mathrm{s}]$

$m_{\text {in }}: \quad$ Air mass flow rate at the channel inlet, $[\mathrm{kg} / \mathrm{s}]$

$\mathrm{Nu}_{\text {local }}$ : Average Nusselt number based on the channel hydraulic diameter, $h D_{h} / k$

$P_{\mathrm{amb}}: \quad$ Ambient (lab) pressure, $[\mathrm{Pa}]$

$P_{\text {channel }}:$ Cross-sectional perimeter, $17.75 \mathrm{~cm}$

$q^{\prime \prime}$ : $\quad$ Total heat flux generated by the foil heater $\left(=v / A_{\text {heater }}\right),\left[\mathrm{W} / \mathrm{m}^{2}\right]$

$q_{b}^{\prime \prime}: \quad$ Total heat loss through the back of the test section wall to the ambient, $\left[\mathrm{W} / \mathrm{m}^{2}\right]$

$q_{r}^{\prime \prime}: \quad$ Total radiation losses from the heated wall to the surrounding unheated walls

$r_{\text {rib }}$ : Rib top corner radii, $0.074 \mathrm{~cm}$ (Figure 1)

Re: Local Reynolds number based on the channel hydraulic diameter and local mass flow rate, $(4 \dot{m} / P \mu)$

$\mathrm{Re}_{\mathrm{in}}$ : Inlet Reynolds number based on the channel hydraulic diameter and inlet mass flow rate, $\left(4 \dot{m}_{\text {in }} / P \mu\right)$

$v$ : $\quad$ Voltage across the surface foil heater, [volts] 
$V:$ Average velocity, $[\mathrm{m} / \mathrm{s}]$

$w$ : Rib width at its root, 0.442 and $0.5 \mathrm{~cm}$

$\beta$ : Channel tilt angle, 22 degrees (Figure 1)

$\Delta P$ : Pressure drop across the rib-roughened section, $[\mathrm{Pa}]$.

\section{Disclosure}

J. S. Halabi is now with Packard International Inc.

\section{Conflict of Interests}

The authors declare that there is no conflict of interests regarding the publication of this paper.

\section{References}

[1] R. E. Chupp, H. E. Helms, P. W. McFadden, and T. R. Brown, "Evaluation of internal heat transfer coefficients for impingement cooled turbine blades," J-aircraft.com, vol. 6, no. 1, pp. 203208, 1969.

[2] R. S. Bunker and D. E. Metzger, "Local heat transfer in internally cooled turbine airfoil leading edge regions. Part I. Impingement cooling without film coolant extraction," Journal of Turbomachinery, vol. 112, no. 3, pp. 451-458, 1990.

[3] R. S. Bunker and D. E. Metzger, "Local heat transfer in internally cooled turbine airfoil leading edge regions. Part II. Impingement cooling with film coolant extraction," Journal of Turbomachinery, vol. 112, no. 3, pp. 459-466, 1990.

[4] H. Chang, D. Zhang, and T. Huang, "Impingement heat transfer from rib roughened surface within arrays of circular jet: the effect of the relative position of the jet hole to the ribs," Paper 97-GT-331, 1997.

[5] K. V. Akella and J.-C. Han, "Impingement cooling in rotating two-pass rectangular channels with ribbed walls," Journal of Thermophysics and Heat Transfer, vol. 13, no. 3, pp. 364-371, 1999.

[6] M. E. Taslim, L. Setayeshgar, and S. D. Spring, "An experimental evaluation of advanced leading edge impingement cooling concepts," Journal of Turbomachinery, vol. 123, no. 1, pp. 147-153, 2001.

[7] M. E. Taslim, Y. Pan, and S. D. Spring, "An experimental study of impingement on roughened airfoil leading-edge walls with film holes," Journal of Turbomachinery, vol. 123, no. 4, pp. 766-773, 2001.

[8] M. E. Taslim, K. Bakhtari, and H. Liu, "Experimental and numerical investigation of impingement on a rib-roughened leading-edge wall," Journal of Turbomachinery, vol. 125, no. 4, pp. 682-691, 2003.

[9] M. E. Taslim and A. Khanicheh, "Experimental and numerical study of impingement on an airfoil leading edge with and without showerhead and gill film holes," Journal of Turbomachinery, vol. 128 , no. 2, pp. 310-320, 2006.

[10] M. E. Taslim and D. Bethka, "Experimental and numerical impingement heat transfer in an airfoil leading-edge cooling channel with cross-flow," Journal of Turbomachinery, vol. 131, no. 1, 7 pages, 2009.

[11] M. E. Taslim and D. Bethka, "Experimental and numerical impingement heat transfer in an airfoil leading-edge cooling channel with cross-flow," Journal of Turbomachinery, vol. 131, no. 1, Article ID 011021, 7 pages, 2009.
[12] D. E. Metzger, C. S. Fan, and J. W. Pennington, "Heat transfer and flow friction characteristics of very rough transverse ribbed surfaces with and without pin fins," in Proceedings of the ASME/JSME Thermal Engineering Joint Conference, vol. 1, 1983, pp. $429-436$.

[13] N. Abuaf, R. Gibbs, and R. Baum, "Pressure drop and heat transfer coefficient distributions in serpentine passages with and without turbulence promoters," in Proceedings of the 8th International Heat Transfer Conference, C. L. Tien, V. P. Carey, and J. K. Ferrel, Eds., pp. 2837-2845, 1986.

[14] S. C. Lau, J. C. Han, and Y. S. Kim, “Turbulent heat transfer and friction in pin fin channels with lateral flow ejection," Journal of Heat Transfer, vol. 111, no. 1, pp. 51-58, 1989.

[15] S. C. Lau, J. C. Han, and T. Batten, "Heat transfer, pressure drop, and mass flow rate in pin fin channels with long and short trailing edge ejection holes," Journal of Turbomachinery, vol. 111, no. 2, pp. 116-123, 1989.

[16] T. K. Kumaran, J. C. Han, and S. C. Lau, "Augmented heat transfer in a pin fin channel with short or long ejection holes," International Journal of Heat and Mass Transfer, vol. 34, no. 10, pp. 2617-2628, 1991.

[17] M. E. Taslim, T. Li, and S. D. Spring, "Experimental study of the effects of bleed holes on heat transfer and pressure drop in trapezoidal passages with tapered turbulators," Journal of Turbomachinery, vol. 117, no. 2, pp. 281-289, 1995.

[18] M. E. Taslim and G. Nicolas, "An experimental and numerical investigation of jet impingement on ribs in an airfoil trailingedge cooling channel," in Proceedings of the 12th International Symposium on Transport Phenomena and Dynamics of Rotating Machinery, Paper \# ISROMAC12-2008-20238, Honolulu, Hawaii, USA, 2008.

[19] M. E. Taslim and A. Nongsaeng, "Experimental and numerical cross-over jet impingement in an airfoil trailing-edge cooling channel," Journal of Turbomachinery, vol. 133, no. 4, pp. 12011210, 2011.

[20] M. E. Taslim and M. K. H. Fong, "Experimental and numerical crossover jet impingement in a rib-roughened airfoil trailingedge cooling channel," Journal of Turbomachinery, vol. 135, no. 3, Article ID 051014, pp. 1-10, 2013.

[21] M. N. Ozisik, Heat Transfer: A Basic Approach, chapter 12, McGraw-Hill, New York, NY, USA, 1985.

[22] J. S. Halabi, Measurements of heat transfer coefficients and friction factors in a rib-roughened tilted trapezoidal channel with bleed holes [M.S. thesis], Mechanical and Industrial Engineering Department, Northeastern University, Boston, Mass, USA, 2006.

[23] S. J. Kline and F. A. McClintock, "Describing uncertainty in single-sample experiments," Mechanical Engineering, vol. 75, pp. 3-8, 1953. 

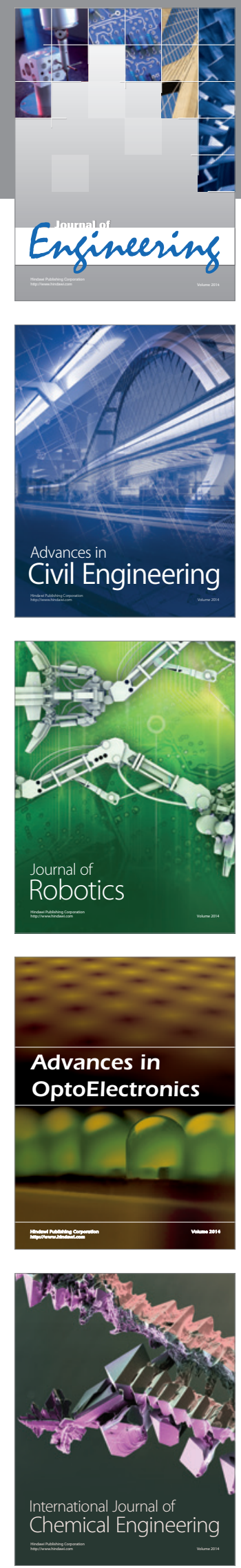

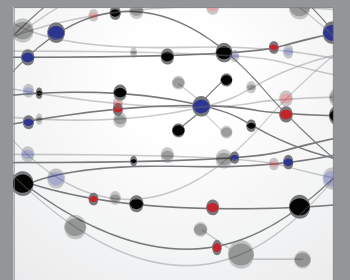

The Scientific World Journal
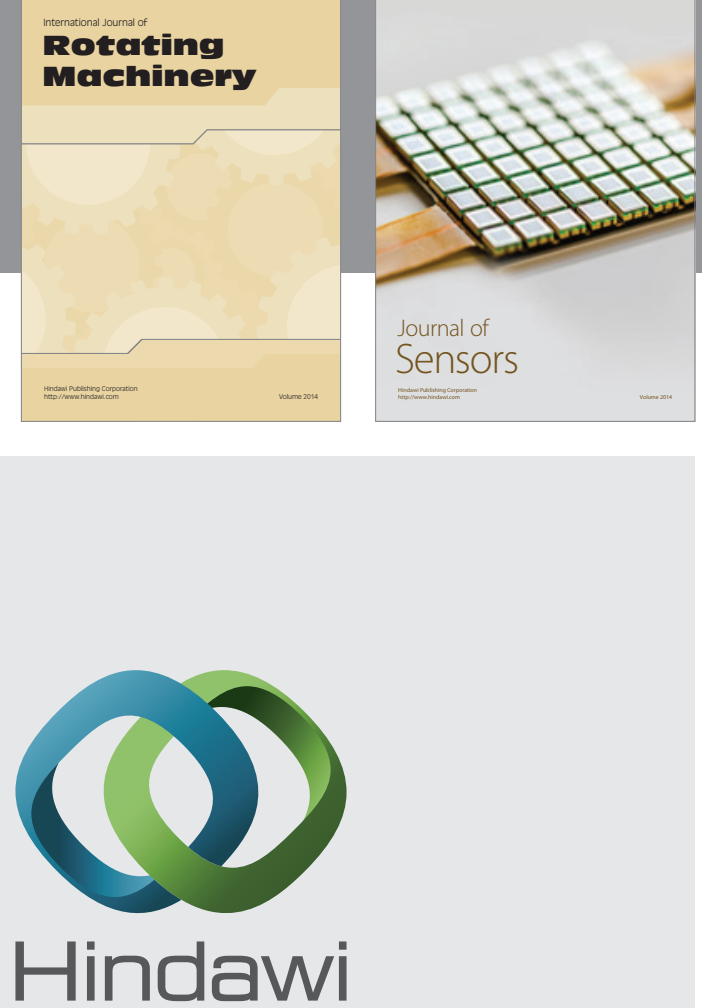

Submit your manuscripts at http://www.hindawi.com
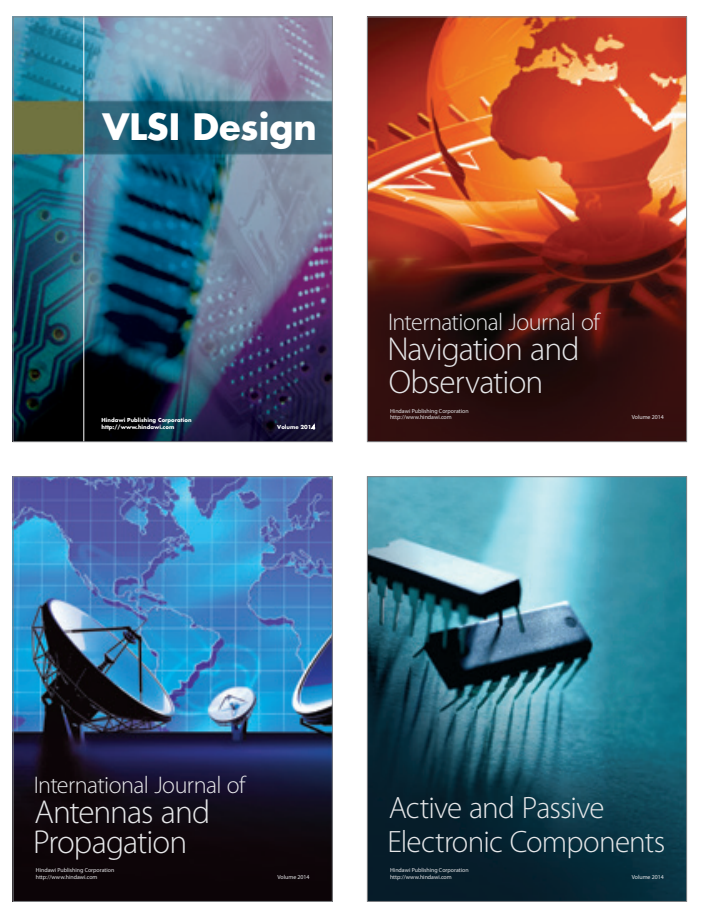
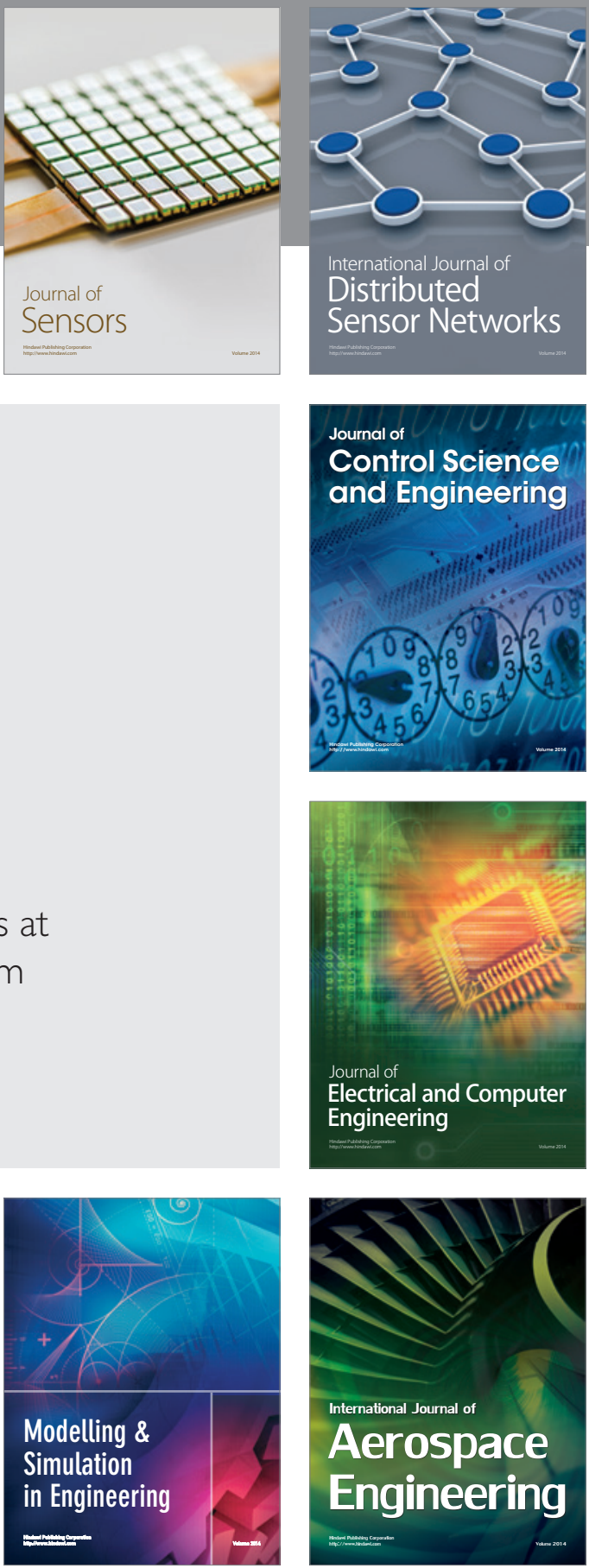

Journal of

Control Science

and Engineering
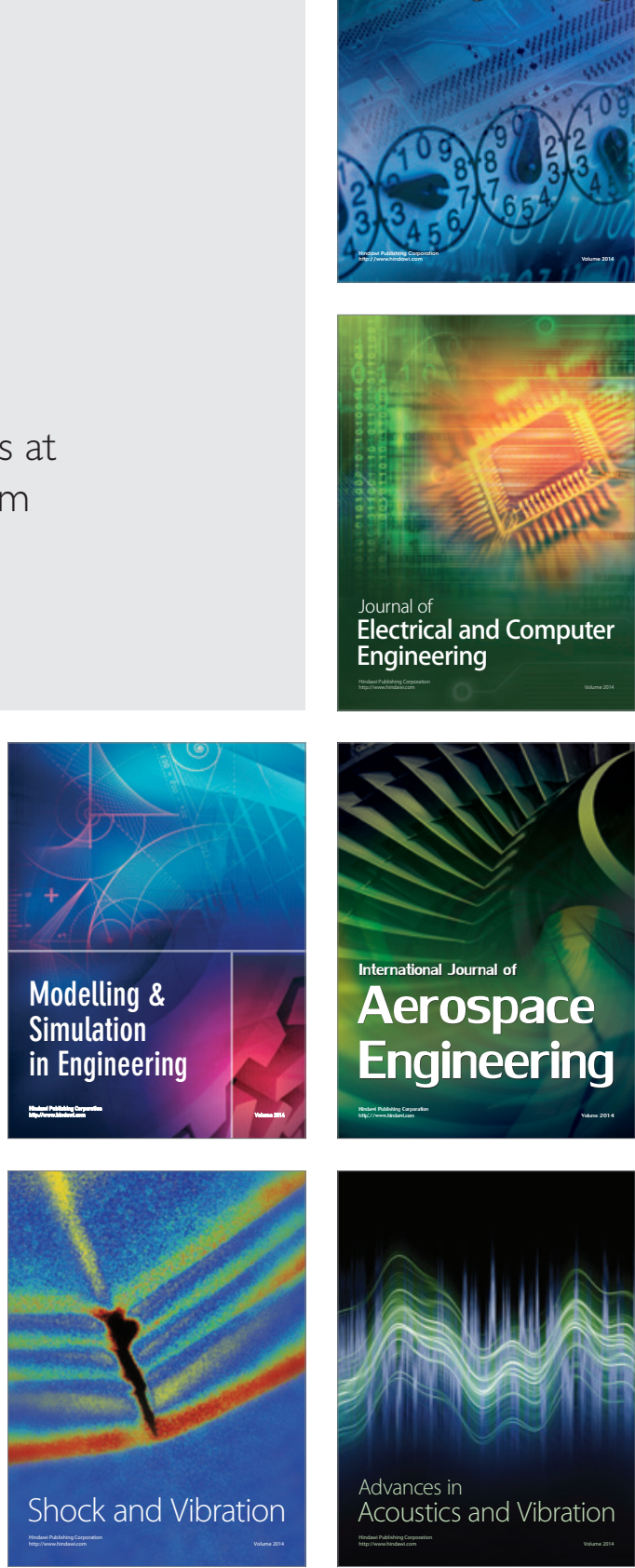